\title{
Surgery for patients with drug-resistant tuberculosis: report of 121 cases receiving community-based treatment in Lima, Peru
}

\author{
Jose G Somocurcio, Alfredo Sotomayor, Sonya Shin, Silvia Portilla, Maria Valcarcel, Dalia Guerra, \\ Jennifer Furin
}

See end of article for authors' affiliations

\section{Correspondence to:} Dr Jennifer Furin, Brigham and Women's Hospital Division of Social Medicine and Health Inequalities, 1620 Tremont Street, Third Floor, Boston, Massachusetts 02120, USA; ifurin@

partners.org

Received 25 August 2005

Accepted 15 June 2006

Published Online First

23 August 2006

\begin{abstract}
Background: While most patients with tuberculosis (TB) can be successfully treated using short-course medical chemotherapy, thoracic surgery is an important adjunctive strategy for many patients with drug-resistant disease. The need for physical, technical and financial resources presents a potential challenge to implementing surgery as a component of treatment for multidrug-resistant TB (MDR-TB) in resource-poor settings. However, a cohort of patients with severe MDR-TB in Lima, Peru underwent surgery as part of their treatment.

Methods: 121 patients underwent pulmonary surgery for drug-resistant tuberculosis between May 1999 and January 2004. Surgery was performed by a team of thoracic surgeons under the Ministry of Health. Patient demographic data, clinical characteristics, surgical procedures and surgical outcomes were studied.

Results: Most of the patients had failed multiple TB regimens and were resistant to a median of seven drugs. The median time of follow-up after surgery was 33 months. $79.3 \%$ of patients were culture-positive before surgery, and sustained culture-negative status among survivors was achieved in $74.8 \%$ of patients. $63 \%$ of those followed up for at least 6 months after surgery were either cured or probably cured. Postoperative complications, observed in $22.6 \%$ of patients, were associated with preoperative haemoptysis, vital capacity $<50 \%$ and low forced expiratory volume in $1 \mathrm{~s}$.

Conclusions: This is one of the largest cohorts with MDR-TB to be treated with surgery, and the first from a resource-poor country. Although surgery is not often considered an option for patients in resource-poor settings, the findings of this study support the argument that adjunctive surgery should be considered an integral component of MDR-TB treatment programmes, even in poor countries such as Peru.
\end{abstract}

M ycobacterium tuberculosis infects more than one-third of the world's population and causes an estimated two to three million deaths annually. ${ }^{1}$ In the 8th World Health Organization (WHO) annual report on global tuberculosis (TB) control, the WHO calculates that there were 8.8 million new cases of TB in 2002, of which 3.9 million were smear-positive. The global incidence of TB (per capita) was reportedly growing at approximately $1.1 \%$ per year, and the absolute number of cases at $2.4 \%$ per year.

Most patients with TB can be successfully treated using short-course medical chemotherapy, which consists of a fourdrug regimen including isoniazid, rifampin, pyrazinamide and ethambutol. ${ }^{2}$ However, a small proportion of patients with pulmonary TB require surgical treatment. ${ }^{3}$ The indications for surgery usually include management of complications of TB (including haemoptysis, bronchiectasis, bronchial stenosis, bronchopleural fistula and aspergilloma) and management of drug-resistant forms of the disease. ${ }^{4-8}$ A wide variety of procedures have been reported, including surgical resection and thoracoplasty. ${ }^{9}$ Patients usually do well with surgery, with cure rates of $60-100 \%$ being achieved..$^{11}$

Multidrug-resistant tuberculosis (MDR-TB) — a major indication for surgery-is defined as strains of $M$ tuberculosis with in vitro resistance to at least isoniazid and rifampin, the two most powerful existing antituberculous agents. ${ }^{12}$ Because of this, treatment is prolonged and complicated (lasting 1824 months) and often requires the use of at least five antibiotics, one of which is received as a daily injection. ${ }^{13}{ }^{14}$ In many countries the rates of MDR-TB are increasing, and more international efforts have been mobilised to confront this emerging infectious disease. ${ }^{15}$ A combined medical and surgical approach is increasingly being used to treat patients with MDR-TB. ${ }^{16}$
Several cohorts of patients with MDR-TB undergoing surgery have been reported in the literature. ${ }^{17-22}$ In general, the studies show excellent microbiological outcomes with low complications rates, but most of the cohorts are small and all are from relatively wealthy countries. To date, there has been no report on the use of surgical treatment for the management of MDRTB under programme conditions in resource-poor settings. This study reports on a cohort of patients with MDR-TB in Lima, Peru who received treatment in conjunction with the Ministry of Health's DOTS-Plus treatment programme.

Peru is one of the poorest countries in Latin America with limited resources for health care. The gross mational product (GNP) of Peru in 2001 was 54000 million US dollars, of which $2.8 \%$ ( 1512 million US dollars) was spent on health, one of the lowest health expenditure figures in the region. Furthermore, Peru's annual expenditure of 28700 million US dollars (approximately $50 \%$ of the GNP) on external debts perpetuates a deplorable socioeconomic situation that contributes to the high prevalence of infectious diseases such as TB. The incidence of TB in Peru is among the highest in South America, with an incidence rate of 134 per 100000 habitants in 2000. ${ }^{23}$ The average annual cost of TB control in Peru is $\$ 94446000$ per year, representing $14 \%$ of the total public health expenditure and $4 \%$ of the total health expenditure. ${ }^{24}$

In the densely populated periphery of metropolitan Lima, where half of all national cases are detected, the risk of infection with $M$ tuberculosis is estimated to be among the highest levels documented recently in any population. ${ }^{25-27}$ Furthermore, the rate of MDR-TB continues to rise despite

Abbreviations: $\mathrm{BMI}$, body mass index; $\mathrm{FEV}_{1}$, forced expiratory volume in $1 \mathrm{~s}$; MDR-TB, multidrug-resistant tuberculosis 


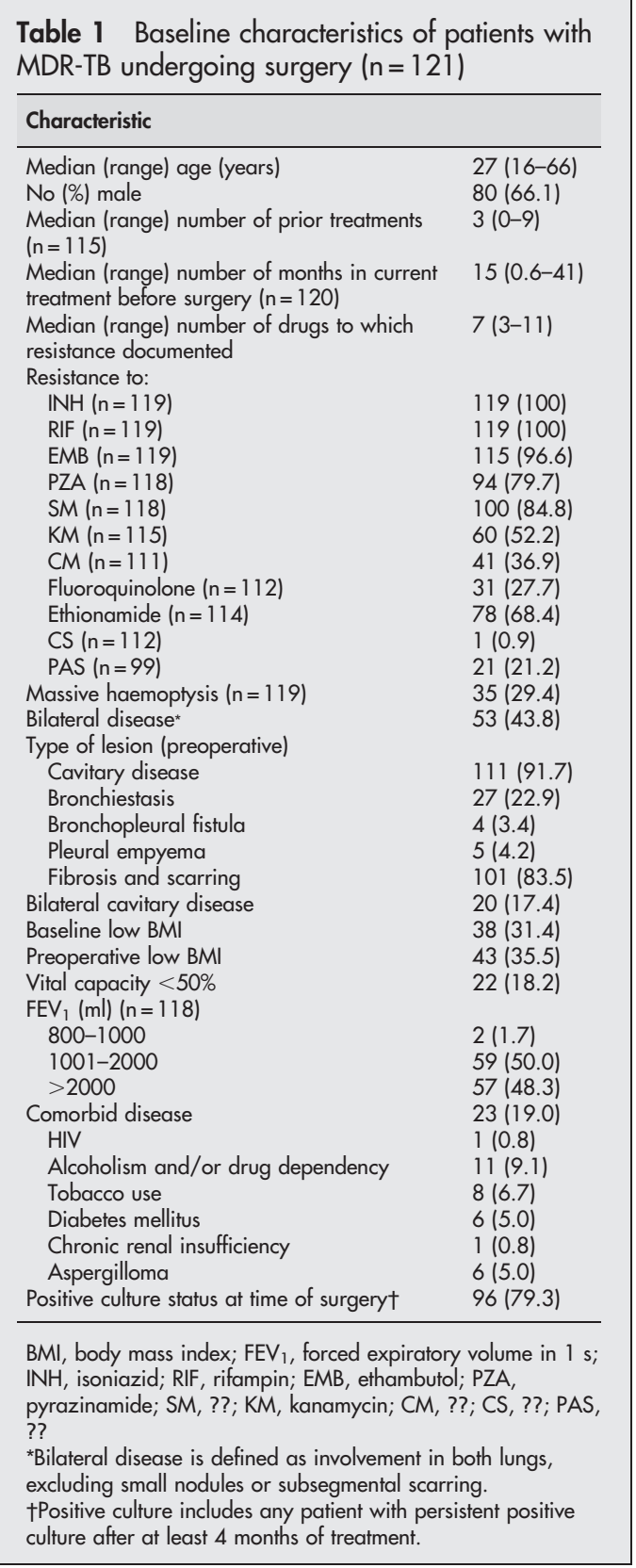

implementation of MDR-TB treatment strategies since 1996, with a national prevalence of $3 \%$ among newly diagnosed TB patients and $12.3 \%$ among those previously treated for TB. ${ }^{28}$

The Peruvian Ministry of Health operates a large and successful National TB Control Program that has been working in partnership with non-governmental organisations since 1996 to provide treatment for patients with MDR-TB. In May 1999 thoracic surgery was incorporated into the MDR-TB treatment programme. ${ }^{29}$ To date, more than 2400 patients with MDRTB have been treated using individualised regimens based on drug susceptibility testing under directly observed therapy. Community-based service has been a key component of this programme, including the use of community health workers to supervise treatment and carry out ambulatory-based management of complex adverse events and complications. Excellent outcomes have been achieved, with a cure rate of more than $80 \%$ in the first cohort. ${ }^{30}$ Since May 1999, 121 patients have undergone thoracic surgery (approximately 5.6\% of the total cohort).

\begin{tabular}{ll}
$\begin{array}{l}\text { Table } 2 \\
(\mathrm{n}=121)\end{array}$ & Initial surgical procedures performed \\
\hline Procedure & Number $(\%)$ \\
\hline Lobectomy & $76(62.8)$ \\
Pneumonectomy & $27(22.3)$ \\
Lobectomy and segmentectomy & $11(9.1)$ \\
Segmentectomy or wedge resection & $3(2.5)$ \\
Other & $4(3.3)$ \\
\hline
\end{tabular}

\section{METHODS}

A prospective case series of 121 patients undergoing pulmonary surgery for MDR-TB between May 1999 and January 2004 was performed. In this cohort, 119 patients had documented MDRTB and two patients had presumed MDR (having failed previous treatments) but drug susceptibility testing could not be obtained at the time of treatment initiation. All drug susceptibility tests were performed at the Massachusetts State Laboratory Institute; the methods have been described elsewhere. $^{30}$

Preoperative evaluation included standard radiography, CT scanning, spirometry, arterial blood gas analysis, routine laboratory analyses and an enzyme-linked inmmunosorbant assay for HIV. Ventilation-perfusion lung scans were performed in patients with marginal spirometric results. The medical and surgical staff evaluated each patient individually to determine their suitability for surgery. Patients were included if they had unilateral or bilateral pulmonary lesions localised to permit resection; sufficient pulmonary reserve to tolerate pulmonary resection as determined by spirometry and assessment of residual parenchyma on preoperative CT scanning; and at least one of the following: (1) poor treatment response (ie, persistent or intermittent positive sputum culture despite at least 4 months of MDR-TB treatment including first and second line drugs based on individualised drug susceptibility testing; (2) infection with highly resistant strains in patients with localised disease amenable to resection; (3) life-threatening haemoptysis; or (4) pulmonary aspergilloma. Patients with a vital capacity $<50 \%$ and forced expiratory volume in $1 \mathrm{~s}\left(\mathrm{FEV}_{1}\right)$ $<800 \mathrm{ml}$, those with cardiac insufficiency evaluated by a cardiologist and patients with severe malnutrition were excluded.

The risks and benefits of surgery, as well as the prognosis with and without a surgical intervention, were discussed with the patient and informed consent was obtained for all patients who underwent surgery. Surgery was performed by a team of thoracic surgeons under the Ministry of Health; most of the procedures took place at a large public hospital in Eastern Lima. Patients were given general anaesthesia combined with a thoracic epidural; in a few cases only general anaesthesia was administered. Patients were intubated with a double lumen endotracheal tube. Immediate postoperative pain was managed with an epidural catheter located at the T6 level, which remained in place for a maximum of $72 \mathrm{~h}$. Antituberculous treatment was suspended at the time of surgery and started again $48 \mathrm{~h}$ later for a period of at least 1 year after surgery. Routine postoperative follow-up was performed in the outpatient clinic.

The study was approved by the human research committee of Harvard Medical School, Boston, Massachusetts.

\section{Analysis of data}

Data were collected on patient demographics, clinical characteristics, surgical procedures and surgical outcomes. All data 


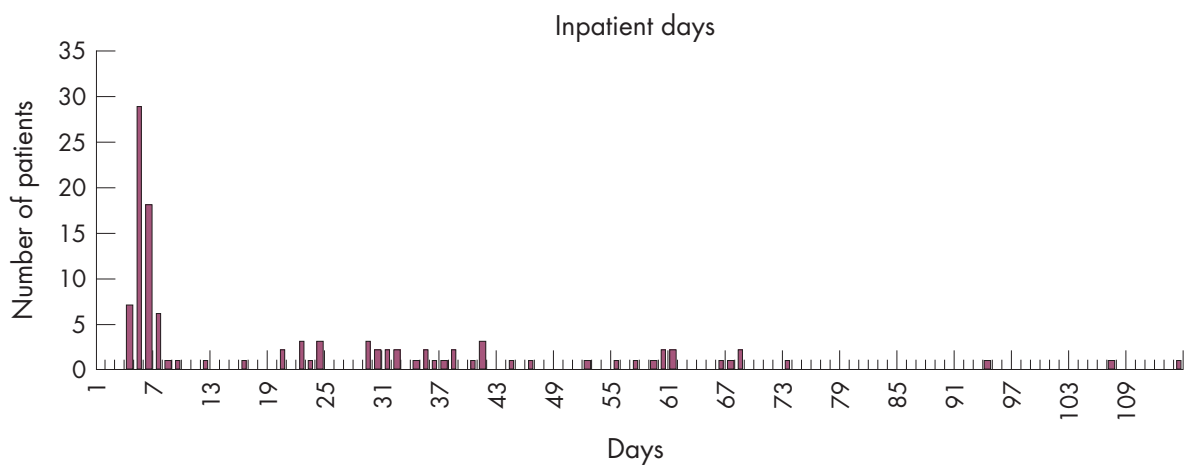

Figure 1 Inpatient days.

were entered into Microsoft Excel and analysed using SAS V.9.1 (SAS Institute Inc, Cary, North Carolina, USA).

\section{RESULTS}

A total of 121 patients underwent 138 procedures during the study period. The demographic and clinical characteristics of the cohort are summarised in table 1. This was a population of chronically ill patients infected with highly drug-resistant strains of $M$ tuberculosis. Most had failed several previous TB regimens and were resistant to a median of 7.0 drugs. Most patients had cavitary disease $(91.7 \%$ ) and $43.8 \%$ had bilateral involvement. Approximately $30 \%$ of the cohort had a low body mass index (defined as $<18.5$ for women and $<20$ for men). One patient underwent surgery before starting MDR-TB treatment; in the remainder, surgery was performed a median of 15 months after starting treatment. The mean number of pulmonary segments affected per patient was 5.0; in most cases more than one lobe was involved. The median follow-up time at analysis was 49 months (range 19-103) and the median followup after surgery was 33 months (range 14-79).

The surgical procedures performed are listed in table 2. Most patients underwent lobectomy $(63.7 \%)$ or pneumonectomy $(21.8 \%)$. Further surgery was required for 13 of the 121 study patients. Of these, 11 underwent one further procedure, one patient had two subsequent operations and one had three further operations. Indications for re-operations included persistent pleural cavity $(n=3)$, fistula $(n=8)$ and haemorrhage $(n=2)$. The median length of stay in hospital for surgery was 7 days (range 4-114), as shown in fig 1 .

Before surgery $20.7 \%$ of patients were culture-negative and $79.3 \%$ were culture-positive. The indications for surgery in culture-negative cases included high-grade drug resistance with a localised lesion, massive haemoptysis and pulmonary aspergilloma. Among the 115 patients for whom follow-up

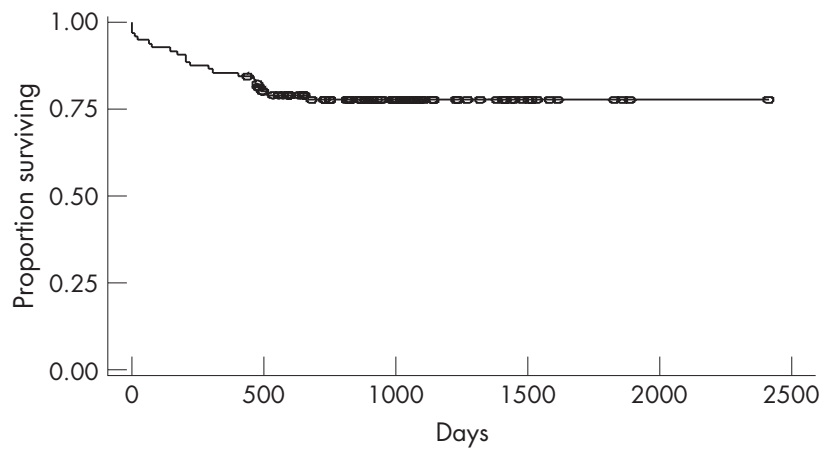

Figure 2 Postoperative survival $(n=121)$. results were available, $78.3 \%$ were culture-negative in the early postoperative period and $74.8 \%$ remained culture-negative at long-term postoperative follow-up. Culture conversion was achieved in the majority of individuals who were culturepositive before surgery: of the 91 individuals who were culturepositive before surgery and who had follow-up results, $72.5 \%$ were culture-negative immediately after surgery and $68.1 \%$ were culture-negative at the time of analysis. The rate of culture conversion also differed depending on whether the patient had unilateral or bilateral disease. Among individuals for whom follow-up data were available, sustained culture conversion was achieved in $85.7 \%$ of patients with unilateral disease compared with $61.5 \%$ of patients with bilateral lesions. Furthermore, the rate of sustained culture conversion was higher $(82.4 \%)$ in patients who underwent lobectomy than in those who underwent pneumonectomy $(60.9 \%)$.

Postoperative mortality within 1 month of surgery in this cohort was $5.0 \%$. Two patients died suddenly, one probably from a pulmonary embolism and one from respiratory insufficiency 6 days after resection. Most of the patients who underwent surgery had substantial respiratory compromise and extensive pulmonary lesions before surgery. In the patient who died from respiratory insufficiency, his vital capacity was $1180 \mathrm{ml}$ (37\% of predicted) and his $\mathrm{FEV}_{1}$ was only $980 \mathrm{ml}$ (36\% predicted). Another patient who died of respiratory insufficiency after a right pneumonectomy had an intact left lung. One patient who died had a history of gastrectomy and died of sepsis and multisystem organ failure. Finally, one patient presented with a pneumothorax on the contralateral side as well as subcutaneous emphysema. This patient required ventilatory support and had ventricular arrhythmias and

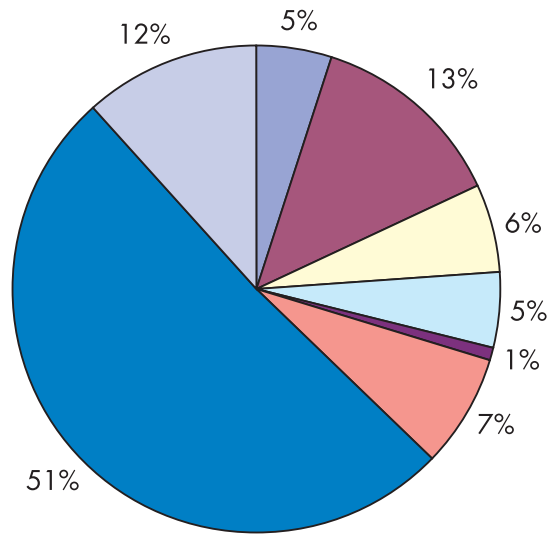

Post-op death $\square$ Non-post-op death $\square$ In Rx, cx pos $\square$ Failed - Relapse $\square$ Abandoned $\square$ Cured $\square$ In Rx, cx neg

Figure 3 Current treatment status $(n=121)$. 


\begin{tabular}{ll} 
Table 3 Postoperative complications $(\mathrm{n}=27)$ \\
\hline Complication & Number \\
\hline Major & \\
Bronchopleural fistula & 8 \\
Empyema & 6 \\
Pulmonary embolus & 2 \\
Haemorrhage & 2 \\
Wound dehiscence & 2 \\
Bronchopneumonia & 2 \\
Respiratory insufficiency & 5 \\
Minor & \\
Wound infection & 6 \\
Prolonged air leak & 5 \\
Recurrent nerve lesion & 2 \\
Pneumothorax & 1 \\
\hline
\end{tabular}

ventricular fibrillation leading to cardiac arrest. Figure 2 shows the postoperative survival in this cohort.

The current treatment status of the study cohort is shown in fig 3; overall, $63.0 \%$ of patients are either cured or probably cured (in treatment, culture-negative).

Twenty-seven patients $(22.6 \%)$ had a total of 43 postoperative complications; 9 experienced minor complications while 19 had major complications (table 3 ).

Univariate analysis showed the following risk factors to be associated with postoperative complications (table 4): preoperative haemoptysis $(\mathrm{p}=0.03)$, low vital capacity $<50 \%$ $(p=0.004)$, low $\mathrm{FEV}_{1}(\mathrm{p}=0.04)$. On the other hand, patients with bilateral disease and low body mass index had higher rates of complications, but these associations were not statistically significant.

\section{DISCUSSION}

A total of 121 patients underwent pulmonary resection. Comparisons with other surgical experiences among patients with MDR-TB are summarised in Appendix 1. Of note, this experience is similar to that of Pomerantz and colleagues ${ }^{17}$ who found that adjuvant surgery greatly improved outcomes in patients with MDR-TB. In addition, our cohort tended to be younger than other cohorts, most of which have been among patients in their third and fourth decades. High-grade drug resistance was observed in our cohort (resistance to a median of seven drugs) compared with the experience of Chiang et al, Park et al, and Sung et al (who described resistance to an average of 3.9, 4.5, and 4.4 drugs, respectively). ${ }^{19-21}$ Only Pomerantz et al ${ }^{17}$ had a cohort with comparable drug resistance, most of whom were resistant to at least six drugs.

In terms of the average number of months of MDR-TB treatment before surgery, our experience is comparable to that of Chiang et al; ${ }^{21}$ other cohorts received surgery earlier in the course of medical treatment for MDR-TB. Of note, the patients in this study had been receiving treatment for a significant time (median 15 months) before undergoing surgery. ${ }^{16}$ In our experience, delays were due to programmatic constraints, particularly related to limited financial resources and difficulty accessing surgical suites. Previous studies have shown that a shorter time interval to surgery is associated with better outcomes. Thus, the excellent results seen in this cohort are even more encouraging. Given the long waiting time to surgery, however, we recognise that there may have been a bias toward patients who were able to survive their disease and receive surgery. More needs to be done to identify likely treatment failures sooner and move them to surgery in a more timely fashion, and our group is currently working towards this goal. Our patients also had short inpatient stays which may have been more cost-effective and allowed for a larger role for surgical management of disease.

Indeed, we have observed that among patients with MDR-TB who fail individualised treatment, extended administration of failing regimens does not contribute to the cure of the patients but permits the infection to disseminate beyond the initial sites of involvement. Such disease progression makes successful pulmonary resection even more challenging. We observed better outcomes in the few patients who were operated upon in the early months of treatment. We therefore advocate early surgical intervention, even if the patient is culture-positive.

In our cohort, $43.8 \%$ of patients had bilateral disease, for whom resection of the dominant lesion was performed. Other series describe cohorts with a predominance of cases with bilateral disease. ${ }^{18-20} 22$ The difference could be due to our exclusion among patients with bilateral disease of those with small nodules and scarring in the contralateral lung. Many other cohorts include in the definition of bilateral disease any evidence of TB in the other lung. Most of our patients had evidence of old TB in the contralateral lung and therefore we felt should not be included in the definition of bilateral disease.

More than half the patients in our cohort had an $\mathrm{FEV}_{1}$ of $<2000 \mathrm{ml}$ and $18 \%$ displayed a limited vital capacity of $<50 \%$. These figures demonstrate the extensive degree of pulmonary compromise and high surgical risk. Park et al ${ }^{19}$ excluded patients with an $\mathrm{FEV}_{1}$ of $<2000 \mathrm{ml}$, based on the experience

Table 4 Risk factors for postoperative complications

\begin{tabular}{lccl}
\hline Variable & Complication & No complication & p Value \\
\hline Male gender & $19(70.4)$ & $61(64.9)$ & 0.59 \\
Mean (SD) age (years) & $34.3(12.5)$ & $29.8(9.4)$ & 0.09 \\
Comorbid condition & $6(22.2)$ & $17(18.1)$ & 0.59 \\
Preoperative haemoptysis & $16(59.3)$ & $34(36.2)$ & 0.03 \\
FEV $<1000 \mathrm{ml}$ & $2(8.0)$ & $0(0)$ & 0.04 \\
Vital capacity $<50 \%$ & $10(37.0)$ & $12(12.8)$ & 0.004 \\
Bilateral disease & $14(51.9)$ & $39(41.5)$ & 0.34 \\
Cavitary disease & $18(69.2)$ & $72(80.9)$ & 0.20 \\
Bilateral cavitary disease & $6(23.1)$ & $14(15.7)$ & 0.39 \\
Preoperative culture-positive status & $21(77.8)$ & $75(79.8)$ & 0.79 \\
Low baseline BMl & $11(40.7)$. & $27(28.7)$ & 0.24 \\
Preoperative low BMI & $13(48.2)$ & $30(31.9)$ & 0.12 \\
Procedure & $14(51.9)$ & $62(66.0)$ & 0.18 \\
$\quad$ Lobectomy & $3(11.1)$ & $8(8.5)$ & 0.71 \\
Pneumonectomy & $8(29.6)$ & $19(20.2)$ & 0.30 \\
Lobectomy + segmentectomy & $2(7.4)$ & $1(1.1)$ & 0.12 \\
Segmentectomy or wedge resection & & \\
\hline FEV, forced expiratory volume in 1 s; BMl, body & mass index. & & \\
\hline
\end{tabular}


in surgical oncology where this threshold is used to define highrisk surgery. ${ }^{31}{ }^{32}$ Unlike cases of lung cancer, however, the chronic nature of pulmonary TB permits a degree of physiological adaptation; we therefore chose not to exclude patients with $\mathrm{FEV}_{1}$ values of $<2000 \mathrm{ml}$ and have succeeded in demonstrating favourable outcomes nonetheless.

While lobectomy was the most common procedure, 27 pneumonectomies were also performed. In other series there was a higher proportion of patients undergoing pneumonectomy $(24.5-74.1 \%)$. It is notable that, among the 20 patients with a vital capacity of $<1800 \mathrm{ml}$ (minimum $1160 \mathrm{ml}$ ) who underwent pneumonectomy, the postoperative mortality was $15 \%$. Most studies have not considered patients within this range of vital capacity for pneumonectomy. Despite the high mortality rate associated with this subgroup of patients, it is conversely notable that $85 \%$ of these patients were able to tolerate the procedure and achieve sustained culture conversion.

We were careful to perform a meticulous dissection; indeed, $90 \%$ of our patients did not require a transfusion. In particular, we avoided excessive dissection of the peribronchial tissue in order to preserve perfusion and thus ensure adequate healing with minimal complications. Nonetheless, eight patients $(6.5 \%)$ experienced bronchopleural fistulas, of which five occurred in patients who were culture-positive at the time of surgery. Three $(3.8 \%)$ of those who underwent lobectomy had postoperative fistulas, while in those undergoing other procedures the rate of bronchopleural fistulas was higher. Chiang et al ${ }^{21}$ reported postoperative fistulas in $3.7 \%$ of his cohort; Kir et al $^{22}$ reported a rate of $7.4 \%$; Park et $a l^{19}$ did not report any bronchopleural fistulas, while $2.9 \%$ of the cohort studied by Pomerantz et $\mathrm{al}^{17}$ experienced fistulas.

One explanation for the higher rate of bronchopleural fistulas in our cohort could be the severe fibrosis in many of our patients, in which the degree of pathological involvement fails to respect segmental boundaries and therefore impedes anatomical segmental resection. In such cases haemostasis is more challenging and the surgical closure of multiple minor bronchi is necessary. Additionally, it is important to take into consideration the poor nutritional status of these patients who generally come from the lower socioeconomic strata of our population. The majority of these fistulas are not of the lobar bronchial stump but are from secondary bronchi, despite the fact that we did not use muscle or adjacent tissue flaps. The persistence of residual pleural space after upper and middle lobectomy procedures was minimised by liberating the triangular ligament in order to favour upward expansion of the remaining lung.

Almost $80 \%$ of the patients in our cohort were culturenegative immediately after surgery and $74.8 \%$ remained culture-negative at the time of follow-up (median 33 months after surgery). All patients continued medical antituberculous treatment after surgery. The proportion of patients who were culture-positive before surgery in our cohort (79\%) is greater than that observed in the other cohorts cited (3.7-69\%). This difference is probably due to our limited resources and the prioritisation of those patients who were deemed least likely to be cured without surgery (ie, those with positive culture status). It is also noteworthy that, among culture-positive patients, $68 \%$ achieved sustained culture conversion with surgery and, even among patients with bilateral disease, $61.5 \%$ were able to maintain culture conversion. Furthermore, among patients who underwent lobectomy, the rate of sustained culture conversion was high $(82.4 \%)$ while in those undergoing pneumonectomy it was somewhat lower $(60.9 \%)$. This finding differs from that reported by Van Leuven $e t a l^{34}$ who observed that pneumonectomy achieves culture conversion more frequently than lobectomy. We observed that successful culture conversion depended not only on the extent of pulmonary resection but also on the successful removal of the most significant lesion. Our results support the approach of minimising surgical resection to the removal of the most affected lesion(s), particularly in patients with low pulmonary reserve.

Among the risk factors associated with postoperative complications, low vital capacity and $\mathrm{FEV}_{1}$ are consistent with other studies. Preoperative haemoptysis was also associated with complications, although this was not statistically significant. Of the variables not associated with postoperative complications, pneumonectomy has been identified as a risk factor in other studies. ${ }^{7}$

The postopererative mortality in our series is similar to that observed in patients undergoing lobectomy and pneumonectomy for cancer. ${ }^{31}$ There were no intraoperative deaths, although the mortality within 30 days of surgery was $5 \%$.

Although surgery is not often considered an option for TB programmes in poor settings, our experience supports the argument that adjunctive surgery should be considered an integral component of MDR-TB treatment programmes, even in poor countries such as Peru. The average cost of surgery in our programme was \$2562. In comparison, the average cost of treating a patient for 18 months within this programme is $\$ 5908$, while the average cost of treating a patient for 24 months is $\$ 7878$. Thus, if performed within the first 6 months of treatment, surgery could not only improve treatment outcomes but also shorten the duration of chemotherapy with little additional cost to the treatment programme.

The cohort reported in this study represents one of the largest surgical experiences with MDR-TB to date and is the first from a resource-poor setting with patients being treated under programme conditions. Excellent outcomes were achieved in the majority of patients with low rates of morbidity and mortality. Despite the fact that most patients had chronic disease and high-grade drug resistance, surgery was an effective adjunctive strategy, resulting in favourable treatment outcomes in $73.7 \%$ of the cohort. Based this experience, we conclude that adjunctive surgery should be considered an integral part of any MDR-TB treatment programme, even in resource-poor settings, as long as adequate surgical expertise and facilities exist. Postoperative morbidity was comparable to other series and was associated with low vital capacity and forced expiratory volume, and preoperative haemoptysis.

\section{Authors' affiliations}

Jose G Somocurcio, Alfredo Sotomayor, Silvia Portilla, Maria Valcarcel, Ministerio de Salud, Lima, Perú

Sonya Shin, Jennifer Furin, Division of Social Medicine and Health Inequalities, Brigham and Women's Hospital, Boston, Massachusetts, USA Dalia Guerra, Socios en Salud, Lima, Peru

This study was funded by grants from the Bill and Melinda Gates Foundation and the Thomas J White Foundation.

Competing interests: None.

\section{REFERENCES}

1 World Health Organization. Global tuberculosis control: WHO report 2002. Geneva: World Health Organization, 2002.

2 American Thoracic Society, Centers for Disease Control and Prevention, Infectious Diseases Society of America. Treatment of tuberculosis. Am J Respir Crit Care Med 2003; 167:603-62.

3 Freixinet J, Rivas J, Rodriguez de Castro F, et al. Role of surgery in pumonary tuberculosis. Med Sci Monitor 2002;8:CR782-6.

4 Souilamas R, Riquet M, Barthers $F$, et al. Surgical treatment of active and sequelar forms of pulmonary tuberculosis. Ann Thorac Surg 2001;71:443-7.

5 Picciocchi A, Granone P, Margaritora S, et al. Surgical management of pulmonary tuberculosis. Rays 1998;23:193-202.

6 Treasure R, Seaworth B. Current role of surgery in Mycobacterium tuberculosis. Ann Thorac Surg 1995;59:1405-9. 
7 Massard G, Dabagh A, Wihlm J, et al. Pneumonectomy for chronic infection is a high-risk procedure. Ann Thorac Surg 1996;62:1033-8

8 Somocurcio JG, Sotomayor A. Tratamiento quirúrgico de la tuberculosis, Capitulo 12.1 st edition. Volume I. Lima, Peru: Fondo Editorial de la UNMSM, 2001.

9 Pomerantz M, Mault J. History of resectional surgery for tuberculosis and other mycobacterial infections. Chest Surg Clin North Am 2000;10:131-3.

10 Perelman M, Strelzov V. Surgery for pulmonary tuberculosis. World J Surg 1997;21:457-67.

11 Lahiri T, Agrawal D, Gupta R, et al. Analysis of status of surgery in thoracic tuberculosis. Indian J Chest Dis Allied Sci 1998:40:99-108.

12 Iseman M. Evolution of drug-resistant tuberculosis: a tale of two species. Proc Natl Acad Sci USA 1994;91:2428-9.

13 Iseman M. Treatment of multidrug-resistant tuberculosis. N Engl J Med 1993:329:784-91.

14 Goble $M$, et al. Treatment of 171 patients with pulmonary tuberculosis resistant to isoniazid and rifampin. N Engl J Med 1993;328:527-32.

15 Program In Infectious Disease and Social Change. The global impact of drug resistant tuberculosis. Boston: Harvard Medical School and the Open Society Institute, 1999.

16 Pomerantz M, Brown J. Surgery in the treatment of multidrug-resistant tuberculosis. Clin Chest Med 1997;18:123-30.

17 Pomerantz B, Cleveland J, Olson $\mathrm{H}$, et al. Pulmonary resection for multidrugresistant tuberculosis. J Thorac Cardiovasc Surg 2001;121:448-53.

18 Iseman M, Madsen L, Goble M, et al. Surgical intervention in the treatment of pulmonary disease caused by drug resistant Mycobacterium tuberculosis. Am Rev Respir Dis 1990;141:623-5.

19 Park S, Lee C, Heu J, et al. A retrospective study for the outcome of pulmonary resection in 49 patients with multidrug-resistant tuberculosis. Int J Tuberc Lung Dis 2002;6:143-9.

20 Sung S, Kang C, Kim Y, et al. Surgery increased the chance of cure in multidrugresistant pulmonary tuberculosis. Eur J Cardiothorac Surg 1999;16:187-93.

21 Chiang $C, Y u M$, Bai K, et al. Pulmonary resection in the treatment of patients with pulmonary multidrug-resistant tuberculosis in Taiwan. Int J Tuberc Lung Dis 2001;5:272-7.
22 Kir A, Tahaoglu K, Okur E, et al. Role of surgery in multidrug-resistant tuberculosis: results of 27 cases. Eur J Cardiothorac Surg 1997;12:531-4.

23 Webb R, Fernández Baca G. Anuario estadístico - Perú en números 2004. Lima, Perú: Edición Instituto Cuánto, 2004

24 Ministerio de Salud. Tuberculosis en el Perú, informe 2000. Dirección General de Salud de las personas. Programa nacional de Control de Enfermedades Transmisibles - Control de la Tuberculosis, Perú, 2001

25 Getchell WS, Davis CE, Gilman J, et al. Basic epidemiology of tuberculosis in Peru: a prevalence study of tuberculin sensitivity in a pueblo joven. Am J Trop Med Hyg 1992;47:721-9.

26 Madico G, Gilman RH, Checkley W, et al. Community infection ratio as an indicator for tuberculosis control. Lancet 1995;345:416-9.

27 Pan American Health Organization-Peru, World Health Organization, Ministerio de Salud-Peru. Report of a review of the National Tuberculosis Control Programme: Peru. Washington, DC: PAHO, 1994.

28 Espinal MA, Laszlo A, Simonsen L, et al. Global trends in resistance to antituberculosis drugs. N Engl J Med 2001;344:1294-303.

29 Farmer P, Kim J. Community-based approaches to the control of multidrug resistant tuberculosis: introducing "DOTS-Plus. " BMJ, 1998;317:671-4

30 Mitnick CD, Bayona J, Palacios E, et al. Community-based therapy for multidrugresistant tuberculosis in Lima, Peru. N Engl J Med 2003;348:119-28.

31 Bave A, et al. Glenn's thoracic and cardiovascular surgery, Volume 1.6th ed. Connecticut: Appleton and Lange, 1996:326,

32 Losso LC. Fsiopatología das resseccoes pulmonares. J Pneumologia 1990;16:39-44.

33 Tahaoğlu K, Törün T, Sevim T, et al. The treatment of multidrug-resistant tuberculosis in Turkey. N Engl J Med 2001;345:170-4.

34 Van Leuven $M$, De Groot $M$, Shean K, et al. Pulmonary resection as an adjunct in the treatment of multiple drug-resistant tuberculosis. Ann Thorac Surg 1997:63:1368-73

\section{APPENDIX 1}

Review of MDR-TB cohorts treated with surgery

\begin{tabular}{|c|c|c|c|c|c|c|c|c|}
\hline & Iseman et $\left.a\right|^{18}$ & Kir et $a l^{22}$ & Sung et al ${ }^{20}$ & Chiang ef $a l^{21}$ & Park et $a l^{19}$ & Pomerantz ef al ${ }^{17}$ & Tahaoğlv et $a l^{33}$ & Van Leuven et $a l^{34}$ \\
\hline Cohort size & 29 & 27 & 27 & 27 & 49 & $\begin{array}{l}172 \text { (includes cohort } \\
\text { described in Iseman } \\
\text { et al }{ }^{8} \text { ) }\end{array}$ & 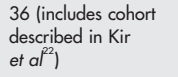 & 62 \\
\hline Time period & 1983-1989 & 1993-1996 & 1/1994-3/1998 & 12/1990-3/1999 & $1 / 1995-12 / 1999$ & $8 / 1983-4 / 2000$ & $3 / 1992-10 / 1999$ & 1/1990-11/1995 \\
\hline $\begin{array}{l}\text { Inclusion/exclusion } \\
\text { criteria }\end{array}$ & $\begin{array}{l}\text { Inclusion: High-grade } \\
\text { drug resistance, } \\
\text { disease sufficiently } \\
\text { localised to resect } \\
\text { preponderance of } \\
\text { disease; sufficient drug } \\
\text { activity to diminish } \\
\text { mycobacterial burden } \\
\text { and allow healing of } \\
\text { bronchial stump }\end{array}$ & $\begin{array}{l}\text { Inclusion: Same as } \\
\text { Iseman et al } \\
\text { Exclusion: HIV } \\
9\end{array}$ & $\begin{array}{l}\text { Inclusion: Positive } \\
\text { sputum despite MDR-TB } \\
\text { therapy or significant } \\
\text { parenchymal damage }\end{array}$ & Inclusion: Not noted & $\begin{array}{l}\text { Inclusion: Failure to } \\
\text { sputum convert or high } \\
\text { risk of relapse due to } \\
\text { remaining cavities } \\
\text { Exclusion: } \mathrm{HIV}, \mathrm{FEV}, \\
<2.0 \text {, heart failure, } \\
\text { renal insufficiency }\end{array}$ & $\begin{array}{l}\text { Inclusion: Same as } \\
\text { Iseman et }\left.a\right|^{18}\end{array}$ & $\begin{array}{l}\text { Inclusion: Same as } \\
\text { Iseman et al }\end{array}$ & $\begin{array}{l}\text { Inclusion: Failure to } \\
\text { convert, previous } \\
\text { relapse(s), high profile } \\
\text { of drug resistance, or } \\
\text { high or potential risk of } \\
\text { relapse (as gauged by } \\
\text { destroyed lung or lobe) }\end{array}$ \\
\hline Bilateral disease & $93.1 \%$ & $59.3 \%$ & $70.4 \%$ & Not described & $63.3 \%$ & Not noted & Not noted & Not noted \\
\hline $\begin{array}{l}\text { Preoperative } \\
\text { bacteriological } \\
\text { status }\end{array}$ & $\begin{array}{l}69.0 \% \text { smear-positive } \\
\text { before surgery }\end{array}$ & $\begin{array}{l}96.3 \% \text { had negative } \\
\text { smear and culture } \\
\text { before surgery }\end{array}$ & $\begin{array}{l}40.7 \% \text { smear-negative } \\
\text { before surgery }\end{array}$ & $\begin{array}{l}22 \% \text { with persistent } \\
\text { culture-positive status } \\
\text { before surgery }\end{array}$ & $\begin{array}{l}63.3 \% \text { culture-positive } \\
\text { before surgery }\end{array}$ & $\begin{array}{l}52.9 \% \text { culture-positive } \\
\text { at time of surgery }\end{array}$ & $\begin{array}{l}94 \% \text { culture-negative } \\
\text { before surgery }\end{array}$ & $\begin{array}{l}39 \% \text { smear and/or } \\
\text { culture positive at } \\
\text { surgery }\end{array}$ \\
\hline $\begin{array}{l}\text { Length of } \\
\text { preoperative } \\
\text { treatment }\end{array}$ & $\begin{array}{l}\text { Median } 5 \text { months } \\
\text { (range 2-12) }\end{array}$ & $\begin{array}{l}\text { Median } 5.8 \text { months } \\
\text { (range 4-8) }\end{array}$ & Median 15 months & $\begin{array}{l}\text { Mean } 10 \text { months } \\
\text { (range 2-23) }\end{array}$ & $\begin{array}{l}20 \text { underwent surgery } \\
\text { within } 3 \text { months of } \\
\text { starting chemotherapy } \\
\text { and } 4 \text { within } 6 \text { months; } \\
7 \text { after } 6 \text { months }\end{array}$ & $\begin{array}{l}3 \text { months in } 20 \\
\text { patients, } 6 \text { months } \\
\text { in } 4 \text { patients; } \\
>6 \text { months in } 7 \\
\text { patients }\end{array}$ & $\begin{array}{l}\text { Mean } 5.9 \text { months } \\
\text { (range 3-10) }\end{array}$ & Not noted \\
\hline $\begin{array}{l}\text { Bacteriological } \\
\text { outcome }\end{array}$ & $\begin{array}{l}\text { Sustained conversion: } \\
87.1 \% \text {; } \\
\text { culture-positive after } \\
\text { surgery: } 6.9 \%\end{array}$ & $\begin{array}{l}100 \% \text { with negative } \\
\text { cultures } 4 \text { months } \\
\text { postoperative; } 3.7 \% \\
\text { relapsed }\end{array}$ & $\begin{array}{l}59.3 \% \text { persistently } \\
\text { culture-positive } \\
\text { postop; at } 29 \text { month } \\
\text { follow-up: } 70.4 \% \\
\text { culture-negative in } \\
\text { treatment }\end{array}$ & $\begin{array}{l}88.9 \% \text { with } \\
\text { postoperative culture } \\
\text { conversion; at } \\
42 \text { months follow-up: } \\
1 \text { later relapsed }\end{array}$ & $\begin{array}{l}90.3 \% \text { of preoperative } \\
\text { positive patients } \\
\text { achieved smear } \\
\text { conversion; } 1 \\
\text { subsequent relapse }\end{array}$ & $\begin{array}{l}\text { At } 7.7 \text { year follow-up: } \\
2 \% \text { remained sputum } \\
\text { positive }\end{array}$ & $\begin{array}{l}89 \% \text { with favourable } \\
\text { outcome (with culture } \\
\text { conversion) }\end{array}$ & $\begin{array}{l}89 \% \text { smear and/or } \\
\text { culture negative } \\
\text { immediately after } \\
\text { surgery; } 80 \% \text { of those } \\
\text { who converted with } \\
\text { surgery remain } \\
\text { disease-free at } \\
36 \text { months }\end{array}$ \\
\hline Surgical outcomes & $\begin{array}{l}\text { Intraoperative deaths: } \\
\text { 0; non-operative } \\
\text { deaths within } \\
30 \text { days: } 3.4(6.8) \% \text {; } \\
\text { complications: } 6.9 \%\end{array}$ & $\begin{array}{l}\text { Operative deaths: } \\
3.7 \% \text {; complications: } \\
14.8 \%\end{array}$ & $\begin{array}{l}\text { Operative deaths: } 0 \\
\text { complications: } 25.9 \%\end{array}$ & $\begin{array}{l}\text { Operative deaths: } 0 \\
\text { vs } 3.7 \% \text {; non- } \\
\text { operative deaths: } 8 \% \text {; } \\
\text { complications: } 11.1 \%\end{array}$ & $\begin{array}{l}\text { Intraoperative deaths: } 0 \text {; } \\
\text { complications: } 16.3 \%\end{array}$ & $\begin{array}{l}\text { Operative deaths } \\
\text { (30 days): } 3.3 \% ; \\
\text { late mortality: } 6.4 \% \text {; } \\
\text { complications: } 11.6 \%\end{array}$ & $\begin{array}{l}\text { Operative deaths } \\
\text { (30 days): } 3.3 \% ; \\
\text { late mortality: } 6.4 \% \text {; } \\
\text { complications: } 11.6 \%\end{array}$ & $\begin{array}{l}\text { Operative deaths } \\
\text { (30 days): } 1.6 \% ; \\
\text { late mortality: } 8.1 \% \text {; } \\
\text { complications: } 23 \%\end{array}$ \\
\hline
\end{tabular}


one year cessation rate in smokers with AL was $10.8 \%$ versus $8.4 \%$ in smokers with NLF (NS)."

Why are these findings being interpreted over-optimistically as evidence of the value of screening for mild COPD? The most likely reason is wishful thinking, since the evidence suggests the opposite conclusion to that supported in the editorial by Mannino. Perhaps it simply arises from the frustrating recognition that COPD is common in adults but is predominantly undiagnosed.

There is a serious consequence from promoting early detection of COPD if there is no evidence that it makes any difference. Putting resources into spirometry for the early detection of COPD draws resources from more effective work, the most compelling of which in this context is general smoking cessation. In the study by Bednarek et al, 71 people needed to be screened for every additional 1 year smoking quit achieved. This is equivalent to a cost of about $€ 650$ per additional smoking quitter.

Smoking cessation is the most important intervention in the primary and secondary prevention of COPD. It is equally important in the primary and secondary prevention of cardiovascular disease and many cancers including lung cancer. Until there is some definite advantage to be gained from the early detection of COPD in improving cessation rates among smokers, there is no justification for promoting spirometric screening for mild COPD as a separate public health strategy. On current evidence, screening to detect mild COPD is not warranted and will waste resources that would be better employed to promote smoking cessation in general.

Patrick White

Department of General Practice and Primary Care, King's College London, 5 Lambeth Walk, London SE1 1 6SP, UK; patrick.white@kcl.ac.uk

\section{References}

1 Bednarek M, Gorecka D, Wielgomas J, et al. Smokers with airway obstruction are more likely to quit smoking. Thorax 2006;61:869-73.

2 Mannino DM. Spirometric screening: does it work? Thorax 2006:61:834-5.

3 Gorecka D, Bednarek M, Nowinski A, et al. Diagnosis of airflow limitation combined with smoking cessation advice increases stop-smoking rate. Chest 2003;123:1916-23.

4 Zielinski J, Bednarek M, Gorecka D. [National Program of Early Detection and Prevention of COPD in the years 2000-2002]. Pneumonol Alergol Pol 2005;73:116-21.

\section{Authors' reply}

The World Health Organisation estimates that chronic obstructive pulmonary disease (COPD) affects 600 million people and that three million die every year from COPD. It is expected that, in 2020, COPD will be the third main cause of death worldwide. ${ }^{1}$ Until now these estimates have proved valid. This worrying situation calls for action.

In the National Program of Early Detection and Prevention of COPD in Poland, >90 000 "healthy" smokers aged 40 years or more performed spirometric tests. It was found that $20.3 \%$ of them had signs of airflow limitation compatible with a diagnosis of COPD, and 72\% of these already had moderate or severe airflow limitation. None had previously consulted their family physician about their respiratory problems and most of them needed immediate further evaluation and treatment. ${ }^{2}$

By combining spirometric testing with antismoking advice, sustained quitting of smoking was achieved in $16 \%$ of the COPD group and $11 \%$ of the "healthy smoker" group. ${ }^{3}$ Similar results were obtained in the earlier pilot study based on a small group of subjects not included in the current study. ${ }^{4}$ These results are better than those obtained by general antismoking advice. ${ }^{5}$ The Lung Health Study confirmed that smoking cessation slows down the accelerated decline in forced expiratory volume in $1 \mathrm{~s}$ which occurs in patients with COPD with newly diagnosed disease. As many as 96.7\% of subjects with moderate COPD who quit smoking still had moderate disease after 11 years of follow-up compared with $81.9 \%$ of those who continued to smoke. The initial success of quitting smoking in this group of patients turned out to be long lasting, with 93\% still non-smokers after 11 years. ${ }^{6}$

Even if the cost of one additional person quitting smoking using our approach is $€ 650$, this is roughly half the cost of 1 year of treatment for one patient with COPD in the UK (US\$1245). ${ }^{7}$ It is also equivalent to the cost of one life-year saved by antismoking advice only, which ranges from $€ 385$ to $€ 797$.

Although there is a lack of evidence of benefit related to the early diagnosis of mild COPD by spirometric testing, ${ }^{9}$ this does not mean that such benefit does not exist. Fifty years ago systemic hypertension was frequently diagnosed when a patient had a stroke. Now early diagnosis and treatment of systemic hypertension are obligatory.

Early diagnosis of COPD defines a group of smokers at risk not only for the progression of COPD but also for lung cancer or ischaemic heart disease. Antismoking advice is an integral part of early diagnosis which will prevent many deaths from these diseases. For evidence of the benefits, we will have to wait.

Michal Bednarek, Dorota Gorecka, Jan Zielinski

2nd Department of Respiratory Medicine, National Research Institute of TB and Lung Diseases, 26 Plocka St 01-138 Warsaw, Poland; m.bednarek@igichp.edu.pl

\section{References}

1 Murray RP, Anthonisen NR, Connett JE, et al. Effects of multiple attempts to quit smoking and relapses to smoking on pulmonary function. Lung Health Study Research Group. J Clin Epidemiol 1998;51:1317-26.

2 Zielinski J, Bednarek M, Gorecka D, et al. Increasing COPD awareness. Eur Respir J 2006;27:833-52.

3 Bednarek M, Gorecka D, Wielgomas J, et al. Smokers with airway obstruction are more likely to quit smoking. Thorax 2006;61:869-73.

4 Górecka D, Bednarek M, Nowinski A, et al. Diagnosis of airflow limitation combined with smoking cessation advice increases stop smoking rate. Chest 2003;123:1916-23.

5 Silagy C, Stead LF. Physician advice for smoking cessation. Cochrane Database Syst Rev, 2001 ;CD000165.

6 Anthonisen NR, Connett JE, Murray RP. Smoking and lung function of Lung Health Study participants after 11 years. Am J Respir Crit Care Med 2002; 166:675-9.

7 Wouters EF. Economic analysis of the Confronting COPD survey: an overview of results. Respir Med 2003;97(Suppl C):S3-14.

8 Cornuz J, Pinget C, Gilbert A, et al. Costeffectiveness analysis of the first-line therapies for nicotine dependence. Eur J Clin Pharmacol 2003;59:201-6.

9 Agency for Healthcare Research and Quality. Use of spirometry for case finding, diagnosis, and management of chronic obstructive pulmonary disease (COPD). AHRQ Publication No 05-E017-2, 2005. www.ahrq.gov/downloads/pub/evidence/ $\mathrm{pdf} / \mathrm{spirocopd} /$ spiro.pdf (accessed 10 April 2006).

\section{CORRECTION}

doi: 10.1136/thx.2005.051961corr 1

In table 1 of Somocurcio JG, Sotomayor A, Shin S, et al (Surgery for patients with drugresistant tuberculosis: report of 121 cases receiving community-based treatment in Lima, Peru. Thorax 2007;62:416-21) in the May issue the expansions of the abbreviations SM, CM, CS and PAS are streptomycin, capreomycin, cycloserine and para-aminosalicylic acid, respectively. 